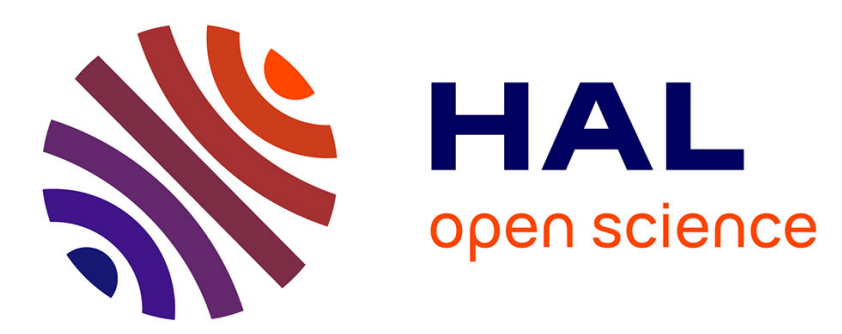

\title{
Seasonal changes in the vertical distribution of two types of multicellular magnetotactic prokaryotes in the sediment of Lake Yuehu, China
}

J. Liu, W. Zhang, H. Du, X. Leng, J.H. Li, H. Pan, J. Xu, Long-Fei Wu, Xiao T.

\section{To cite this version:}

J. Liu, W. Zhang, H. Du, X. Leng, J.H. Li, et al.. Seasonal changes in the vertical distribution of two types of multicellular magnetotactic prokaryotes in the sediment of Lake Yuehu, China. Environmental Microbiology Reports, 2018, 10 (4), pp.475-484. 10.1111/1758-2229.12652 . hal-01954290

\section{HAL Id: hal-01954290 \\ https://hal-amu.archives-ouvertes.fr/hal-01954290}

Submitted on 25 May 2021

HAL is a multi-disciplinary open access archive for the deposit and dissemination of scientific research documents, whether they are published or not. The documents may come from teaching and research institutions in France or abroad, or from public or private research centers.
L'archive ouverte pluridisciplinaire HAL, est destinée au dépôt et à la diffusion de documents scientifiques de niveau recherche, publiés ou non, émanant des établissements d'enseignement et de recherche français ou étrangers, des laboratoires publics ou privés. 


\section{Seasonal changes in the vertical distribution of two types of multicellular magnetotactic prokaryotes in the sediment of Lake Yuehu, China}

Jia Liu (D), 1,2,3 Wenyan Zhang, 1,2,4 Haijian Du, 1,2 Xiaoyun Leng, ${ }^{5}$ Jin-Hua Li, 2,4,6 Hongmiao Pan, 1,2,4 Jianhong $\mathrm{Xu},{ }^{1}$ Long-Fei $\mathrm{Wu}^{4,7}$ and Tian $\mathrm{Xiao}^{1,2,4 *}$ ${ }^{1}$ CAS Key Laboratory of Marine Ecology and Environmental Sciences, Institute of Oceanology Chinese Academy of Sciences, Qingdao 266071, China.

2Laboratory for Marine Ecology and Environmental Science, Qingdao National Laboratory for Marine Science and Technology, Qingdao 266237, China. ${ }^{3}$ College of Earth Science, University of Chinese Academy of Sciences, Beijing 100864, China. ${ }^{4}$ International Associated Laboratory of Evolution and Development of Magnetotactic Multicellular Organisms (LIA-MagMC), CNRS-CAS, Marseille, Beijing-QingdaoSanya.

${ }^{5}$ College of Marine and Environmental Sciences, Tianjin University of Science and Technology, Tianjin 300457, PR China.

${ }^{6}$ Key Laboratory of Earth and Planetary Physics, Institute of Geology and Geophysics, Chinese Academy of Sciences, Beijing 100029, China.

${ }^{7}$ Aix-Marseille Univ, CNRS, LCB, Marseille, 31 chemin Joseph Aiguier, F-13402, France.

\section{Summary}

There are two genetically distinct morphological types of multicellular magnetotactic prokaryotes (MMPs) in the intertidal zone of Lake Yuehu (China): ellipsoidal MMPs (eMMPs) and spherical MMPs (sMMPs). We studied the vertical distribution of both types of MMPs in the sediment at Lake Yuehu during 1 year. Both types of MMPs were observed at sediment depths ranging from 1 to $34 \mathrm{~cm}$, depending on the seasons. The eMMPs distributed at depths of 2-34 cm during spring, 1-11 cm during summer, 2-21 cm during autumn and 9-32 cm during winter. The eMMP species Candidatus Magnetananas rongchenensis, with magnetite magnetosomes, dominated at all distribution

*For correspondence. E-mail txiao@ qdio.ac.cn; Tel. 86-532-82898586; Fax 86-532-82898586. depths. These results suggested that $\mathrm{Ca}$. M. rongchenensis migrated vertically during four seasons. The vertical profiles of oxidation-reduction potential (ORP) in Lake Yuehu changed seasonally, and these changes coincided with the seasonal distribution of MMPs, suggesting that the ORP affected the vertical distribution of MMPs. In addition, high concentrations of ammonium and silicate were associated with low abundances of MMPs.

\section{Introduction}

Magnetotactic bacteria (MTB) synthesize magnetosomes (intracellular single-magnetic-domain crystals) that allow them to orient and navigate along geomagnetic field lines. Multicellular magnetotactic prokaryotes (MMPs) are gram-negative cell aggregates (Farina et al., 1983; Amann et al., 2006; Keim et al., 2006; Lefèvre et al., 2010; Kolinko et al., 2012) that are unique because of their synchronized cell division and coordination of complex movements (Keim et al., 2004b; Abreu et al., 2007). There are two genetically distinct morphotypes of MMPs. The spherical MMPs (sMMPs) are 3-12 $\mu \mathrm{m}$ in diameter and comprise 10-40 cells arranged with helical symmetry (Keim et al., 2006; Abreu et al., 2007; Wenter et al., 2009; Zhang et al., 2014a). The ellipsoidal MMPs (eMMPs) are 8-23 $\mu \mathrm{m}$ long, 7-17 $\mu \mathrm{m}$ wide and comprise 28-101 cells arranged in interlaced circles (Lefèvre et al., 2007; Zhou et al., 2012; Chen et al., 2015). The sMMPs were first discovered in a brackish lagoon in Brazil (Farina et al., 1983) and have a wide geographic distribution in sediments (Rodgers et al., 1990; Keim et al., 2004a; Keim et al., 2004b; Greenberg et al., 2005; Simmons and Edwards, 2007; Wenter et al., 2009; Zhou et al., 2011; Zhang et al., 2014a) and chemically stratified waters (Simmons et al., 2004; Moskowitz et al., 2008). In contrast, eMMPs are known from only the intertidal sediments of a few coastal areas (Lefèvre et al., 2007; Zhou et al., 2012; Chen et al., 2015; Chen et al., 2016).

In aquatic environments, sMMPs with greigite magnetosomes occur at the base of the oxic-anoxic interface $(\mathrm{OAI})$ or in the anoxic zone below the OAI, but 
unicellular MTB, such as cocci and short rods, occur within the OAI (Simmons et al., 2004; Simmons et al., 2007; Moskowitz et al., 2008). The first study of the vertical distribution of sMMPs in sediments occurred in the Araruama Lagoon (Brazil) and reports that sMMPs exist within the anaerobic zone, especially in the top $4.0 \mathrm{~cm}$ layer of sediment (Abreu et al., 2007). A study in the Wadden Sea (Germany) reports that $95 \%$ of sMMPs are present in a 5 to $10 \mathrm{~mm}$ layer at the upper boundary of the black FeS-containing sediment layer (Wenter et al., 2009). A study in Praia da Baleia (Brazil) reports the greatest abundance of sMMPs within the oxycline during June and a very different vertical distribution during March (Sobrinho et al., 2011). A previous study in Huiquan Bay (Shandong Province, China) reports a wider and deeper vertical distribution of magnetiteproducing sMMPs during November. Specifically, sMMPs are present from depths of 2 to $16 \mathrm{~cm}$, with a maximum abundance at approximately $10 \mathrm{~cm}$ (Zhou et al., 2013). In a 45 day microcosm experiment, the vertical distribution of SMMPs was shown to change as they moved to the upper layers, apparently in search of a new microniche (Martins et al., 2012). Although there are a few studies on the vertical distributions of SMMPs, only a few centimetres of upper sediment have been examined. However, there are no detailed studies of the distribution of SMMPs at greater depths. Moreover, little is known about the vertical distribution of eMMPs or the seasonal changes in the vertical distribution of SMMPs and eMMPs.

Recent studies have reported a new species of SMMP (Candidatus Magnetomorum rongchengroseum) and a new species of eMMP (Candidatus Magnetananas rongchenensis) in the intertidal sediment of Lake Yuehu (Rongcheng City, China). The sMMPs in this location contain only magnetite-type magnetosomes or both magnetite-type and greigite-type magnetosomes (Zhou et al., 2011; Zhang et al., 2014a). In contrast, eMMPs with bullet-shaped magnetite magnetosomes occur in most cases, but eMMPs with both rectangular greigite magnetosomes and bullet-shaped magnetite magnetosomes occasionally occur during autumn (Chen et al., 2015). A further study has reported that the abundance of eMMPs and SMMPs in the top $10 \mathrm{~cm}$ of sediment is high during summer and autumn but low during spring and winter (Du et al., 2015). The abundance of sMMPs always peaks before that of eMMPs. No mechanism has been proposed to explain the impact of environmental factors on MMP abundance.

Lake Yuehu $\left(36^{\circ} 43^{\prime}-37^{\circ} 27^{\prime} \mathrm{N}, 122^{\circ} 09^{\prime}-122^{\circ} 42^{\prime} \mathrm{E}\right.$, approximately $4.94 \mathrm{~km}^{2}$ ), also known as Swan Lake, is a shallow coastal lagoon with stabilized semi-diurnal tides and limited human activities located on the east side of the Shandong Peninsula (China). The four seasons at Lake Yuehu are distinct, and throughout the year, the temperature of the sediment ranges from -0.1 to $27.4^{\circ} \mathrm{C}$, the $\mathrm{pH}$ ranges from 7.43 to 8.60 and the mean annual salinity (SAL) is $28.0 \%$. The sediment consists of well-proportioned fine sand with yellow surface layers, grey subsurface layers and black deep layers that is due to changes in sulfur content with depth (Zhang et al., 2014a; Chen et al., 2015; Du et al., 2015). Previous studies have reported the biological characteristics and temporal distribution of MMPs in the top $10 \mathrm{~cm}$ of sediment in Lake Yuehu (Zhang et al., 2014a; Chen et al., 2015; Du et al., 2015), but little is known about the vertical distribution of these MMPs. Here, we report a detailed and systematic investigation of the vertical distribution of eMMPs and SMMPs in Lake Yuehu and try to gain insight into the physiological mechanism.

\section{Results and discussion}

Seasonal changes in the vertical distribution of eMMPs and $S M M P S$

MMPs were present in top $34 \mathrm{~cm}$ of sediment in the intertidal zone of Lake Yuehu (Fig. 1A and B). Analysis by depth and season indicated that the maximum abundance of eMMPs was 148 individuals per $\mathrm{cm}^{3}\left(\mathrm{ind} / \mathrm{cm}^{3}\right)$ at $4 \mathrm{~cm}$ in depth during autumn and the maximum abundance of sMMPs was $182 \mathrm{ind} / \mathrm{cm}^{3}$ at $5 \mathrm{~cm}$ during summer (Table 1).

There were seasonal variations in the vertical distribution of eMMPs (Fig. 1A). During spring, eMMPs occurred at depths of 2 to $34 \mathrm{~cm}$. The maximum abundance of eMMPs was at $6 \mathrm{~cm}\left(127 \mathrm{ind} / \mathrm{cm}^{3}\right.$, Fig. 1A; Table 1). During summer, eMMPs were in the top 1 to $11 \mathrm{~cm}$ of sediment, with a maximum abundance at $5 \mathrm{~cm}$ (72 ind $\left./ \mathrm{cm}^{3}\right)$. During autumn, eMMPs were present at depths of 2 to $21 \mathrm{~cm}$, with a maximum abundance at $4 \mathrm{~cm}\left(148 \mathrm{ind} / \mathrm{cm}^{3}\right)$. During winter, eMMPs were present at depths of 9 to $32 \mathrm{~cm}$, with a maximum abundance at $19 \mathrm{~cm}\left(89 \mathrm{ind} / \mathrm{cm}^{3}\right)$. Thus, eMMPs generally occurred in shallow layers during summer, in middle layers during spring and autumn and in deep layers during winter.

There were also seasonal variations in the vertical distribution of sMMPs (Fig. 1B). During spring, sMMPs were present at depths of 3 to $27 \mathrm{~cm}$; during summer, 1 to $18 \mathrm{~cm}$; during autumn, 1 to $21 \mathrm{~cm}$; and during winter, most sMMPs were at depths of 10 to $30 \mathrm{~cm}$ (Fig. 1B; Table 1). The maximum abundance of sMMPs was at the upper layers of sediment during spring $\left(134 \mathrm{ind} / \mathrm{cm}^{3}\right.$, $5 \mathrm{~cm})$, summer $\left(182 \mathrm{ind} / \mathrm{cm}^{3}, 5 \mathrm{~cm}\right)$ and autumn $\left(125 \mathrm{ind} / \mathrm{cm}^{3}, 3 \mathrm{~cm}\right.$ ) but at the deep layers during winter (37 ind $/ \mathrm{cm}^{3}, 23 \mathrm{~cm}$ ).

Thus, our data showed wide ranges of vertical distributions of sMMPs and eMMPs, especially the distribution ranges in spring, which spanned $25 \mathrm{~cm}$ (3 to 


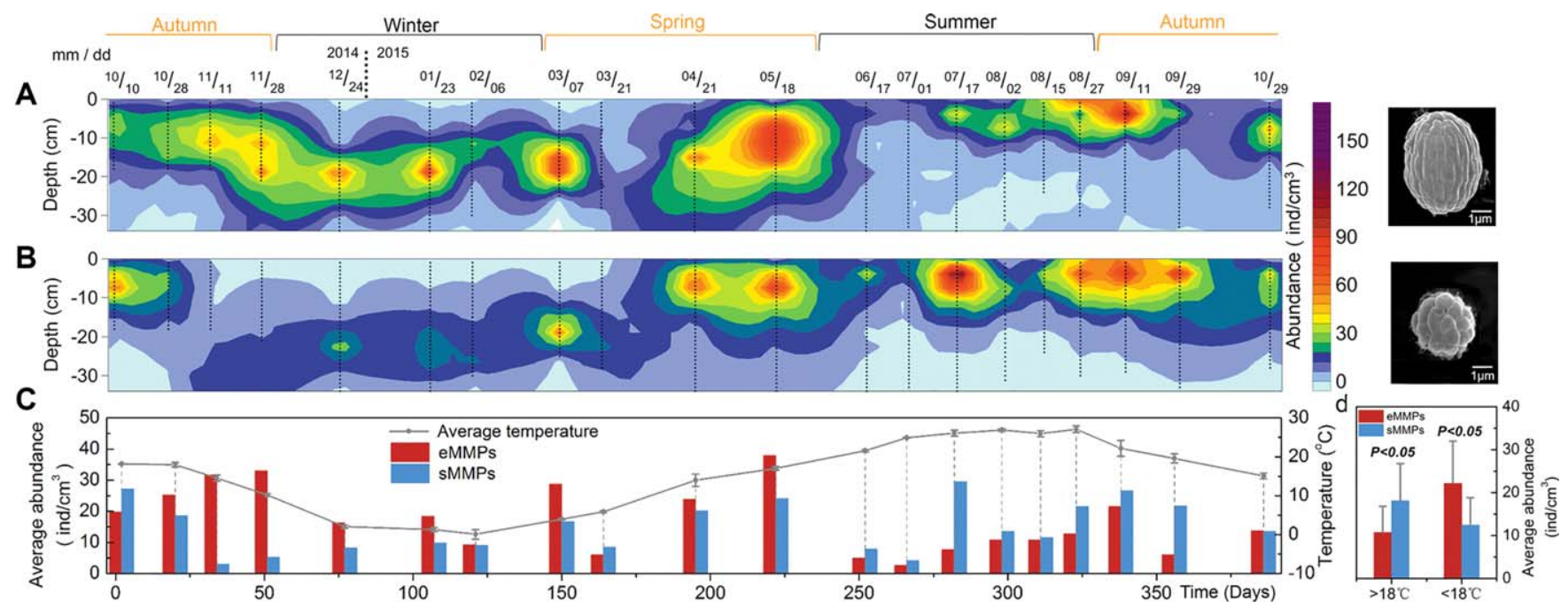

Fig. 1. Abundance of eMMPs and sMMPs at different sediment depths.

The sampling site $\left(37^{\circ} 21^{\prime} 33.857^{\prime \prime} \mathrm{N}, 122^{\circ} 34^{\prime} 41.571^{\prime \prime} \mathrm{E}\right)$ is on the north side of Lake Yuehu. We sampled 20 times from October 2014 to October 2015 at low tide, when the sampling site was exposed to the air. The sampling frequency was once per month during winter and spring and every 2 weeks during summer and autumn. We made two replicates for MMP observations at each sampling date. The distance between two replicate cores was $10 \mathrm{~cm}$. Samples were sliced at $1 \mathrm{~cm}$ intervals to count the MMP abundance. The south poles of two magnetic discs (approximately 300 Gauss) were placed on opposite sides of a sample bottle for $40 \mathrm{~min}$. Then, $2 \mathrm{ml}$ samples near each magnet were removed and transferred into microtubes. A $30 \mu \mathrm{l}$ mixed water sample from the microtube was examined using the hanging drop method under an Olympus BX51 microscope (Tokyo, Japan) equipped with a differential interference contrast (DIC) system.

A and B. Abundance (left) and representative scanning electron microscopy (SEM) photomicrographs (right) of eMMPs (top) and sMMPs (bottom) at different sediment depths during one year. Black dots indicate the sediment layers of each sample.

C. Average abundance of eMMPs (red bars) and SMMPs (blue bars) in each sediment core. The line and error bars indicate the average temperature of the sediment column and standard deviations.

D. Student's $t$-test (significance level: $p<0.05$ ) was used to compare the average abundances of eMMPs and sMMPs at different temperatures using SPSS version 12.0. This test indicated that the overall average abundance of eMMPs was low when the temperature was above $18^{\circ} \mathrm{C}$ but high when the temperature was below $18^{\circ} \mathrm{C}(p<0.05$ for both comparisons).

$27 \mathrm{~cm})$ and $33 \mathrm{~cm}(2$ to $34 \mathrm{~cm})$ respectively. Furthermore, both eMMPs and sMMPs changed their vertical distributions with seasons. Conversely, unicellular MTB were observed only in less than $10 \mathrm{~cm}$ of the surface sediment throughout the year. The wide and variable vertical distribution seems to be unique to MMPs. The vertical distributions of eMMPs and sMMPs were quite different according to present data, which suggested their differences in ecological niches and environmental adaptability.

\section{Identification of eMMP species}

We used micromanipulation to sort eMMPs collected from different sediment depths in each season. We identified

Table 1. Abundance of eMMPs and SMMPs during the four seasons
30 eMMP individuals and 197 eMMP sequences during spring and 70 individuals and 335 sequences during autumn (Table 2). All the eMMP sequences had 100\% sequence identity to $\mathrm{Ca}$. M. rongchenensis. During summer, we identified 15 eMMP individuals at depths of 1$8 \mathrm{~cm}$ and obtained $76 \mathrm{eMMP}$ sequences. During winter, we identified 34 eMMP individuals from the deep sediment and 4 eMMP individuals from the top $3-4 \mathrm{~cm}$ of the sediment and obtained 262 eMMP sequences. Again, all eMMP sequences had $100 \%$ sequence identity to $\mathrm{Ca}$. M. rongchenensis. These results indicated that $\mathrm{Ca}$. M. rongchenensis was the dominant eMMP species at all sediment depths in all four seasons and that there was no seasonal replacement with other eMMP species. Thus, it

\begin{tabular}{|c|c|c|c|c|c|c|c|c|}
\hline & \multicolumn{4}{|c|}{ eMMPs } & \multicolumn{4}{|c|}{ sMMPs } \\
\hline & $\mathrm{DD}(\mathrm{cm})$ & $\begin{array}{c}\mathrm{MA} \\
\text { (ind } / \mathrm{cm}^{3} \text { ) }\end{array}$ & LMA (cm) & $\begin{array}{c}\mathrm{AA} \\
\text { (ind } / \mathrm{cm}^{3} \text { ) }\end{array}$ & $\mathrm{DD}(\mathrm{cm})$ & $\mathrm{MA}\left(\mathrm{ind} / \mathrm{cm}^{3}\right.$ ) & LMA (cm) & $\mathrm{AA}\left(\right.$ ind $\left./ \mathrm{cm}^{3}\right)$ \\
\hline Spring & $2-34$ & 127 & 6 & 36 & $3-27$ & 134 & 5 & 33 \\
\hline Summer & $1-11$ & 72 & 5 & 30 & $1-18$ & 182 & 5 & 38 \\
\hline Autumn & $2-21$ & 148 & 4 & 31 & $1-21$ & 125 & 3 & 31 \\
\hline Winter & $9-32$ & 89 & 19 & 30 & $10-30$ & 37 & 23 & 19 \\
\hline
\end{tabular}

DD: distribution depth; MA: maximum abundance; LMA: layer with maximum abundance; AA: average abundance. 


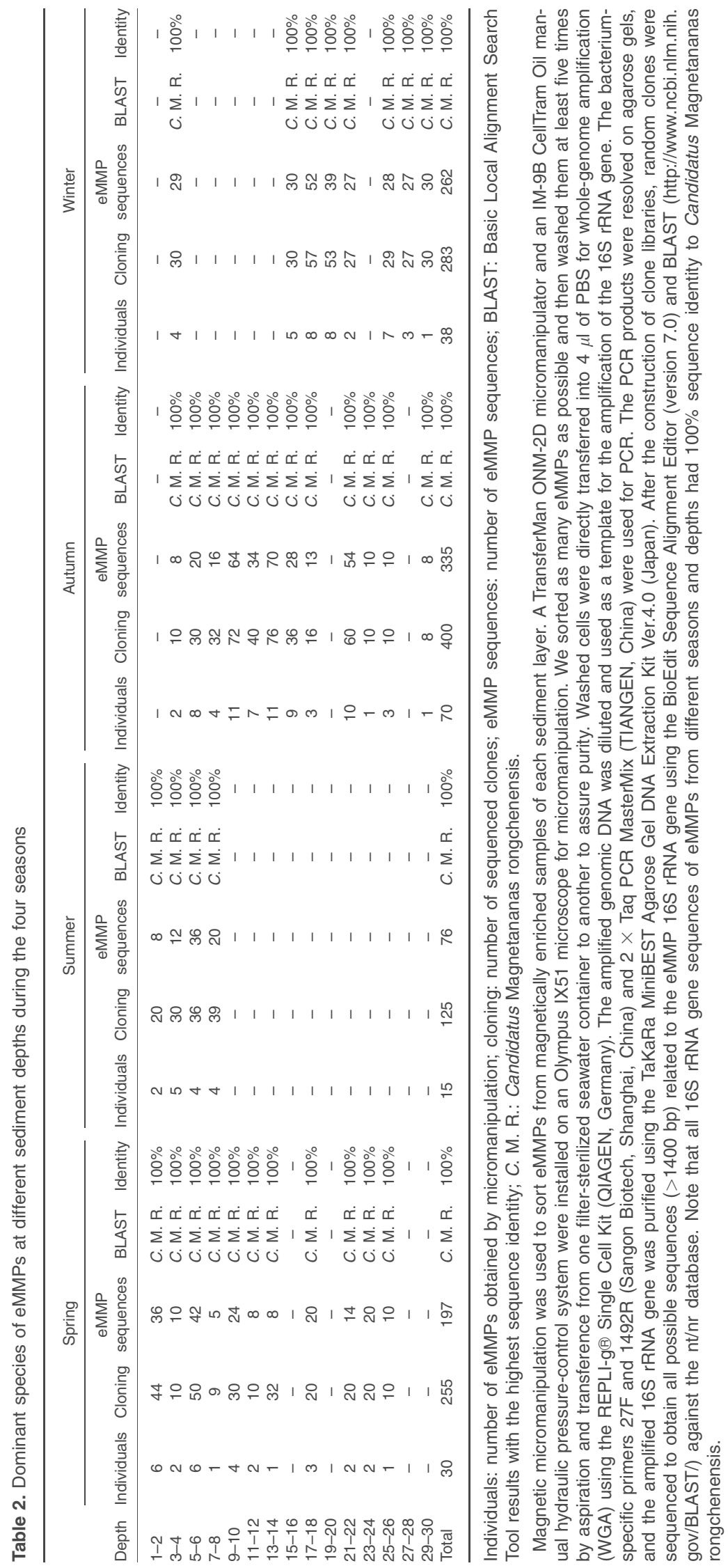


was the seasonal migration of $\mathrm{Ca}$. M. rongchenensis that resulted in the changes in vertical distribution.

Studies on the vertical distribution of Candidatus Magnetoglobus multicellularis (sMMP) in sediment samples (Sobrinho et al., 2011) and in a microcosm experiment (Martins et al., 2012) indicate that changing environmental conditions cause the SMMP population to migrate vertically through the sediment. Our results for Lake Yuehu indicated that the population of $\mathrm{Ca}$. M. rongchenensis migrated seasonally. Seasonal factors might regulate the vertical migration.

\section{Magnetosomes in eMMPs}

A single type of magnetosome was detected in Ca. M. rongchenensis specimens isolated from all sampling depths (Fig. 2A). These magnetosomes were bullet- shaped and composed of iron oxide crystals that commonly consisted solely of magnetite (Bazylinski et al., 2013). The genomic magnetosome island (MAI) from the draft genome of $\mathrm{Ca}$. M. rongchenensis contains the magnetite-producing mamAB-cluster and the mad gene cluster (Leão et al., 2017). Our observation of magnetite magnetosomes indicated that based on the presence of this MAI, the synthesis of magnetosomes in Ca. M. rongchenensis was under genetic control. In addition, the bullet-shaped magnetosomes from 17 to $22 \mathrm{~cm}$ depths of the sediment were not only fewer in number but also smaller in size (Fig. 2B). Furthermore, the magnetosomes there were not well organized into chains (Fig. 2C). These results suggested that the synthesis of magnetite magnetosomes might also be regulated by environmental factors.
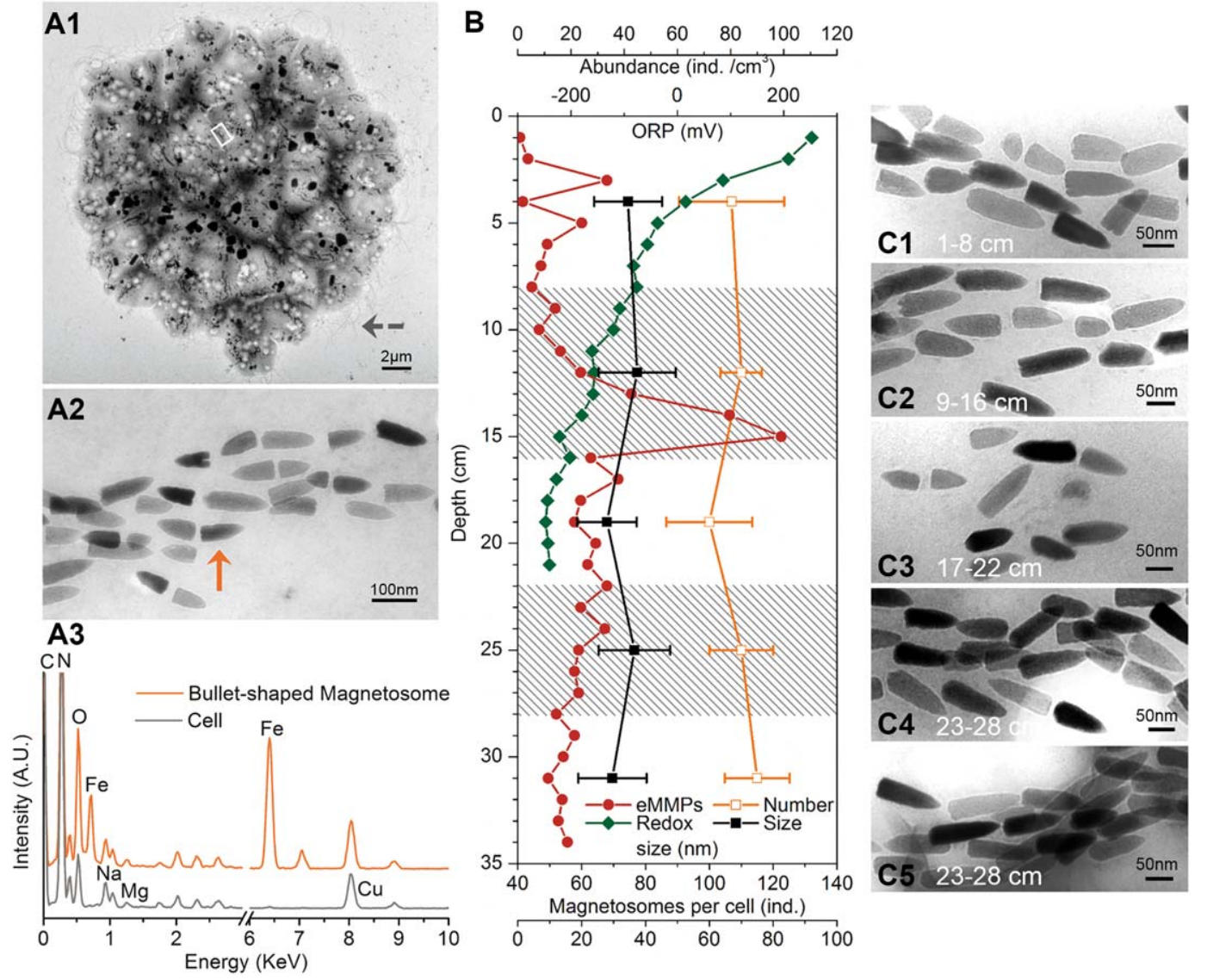

Fig. 2. Magnetosomes of eMMPs from different sediment depths.

Transmission electron microscopy (TEM) observations were made using HITACHI HT770 and JEOL JEM-2100 TEMs operating at accelerating voltages of $100 \mathrm{kV}$ and $200 \mathrm{kV}$ respectively. The JEOL JEM2100 was equipped with an X-MaxN TSR silicon drift detector (Oxford Instruments, UK), which enables chemical microanalysis by energy-dispersive X-ray spectroscopy (EDXS) in the TEM mode. The length and width of magnetosomes were measured using ImageJ 1.50b software, and the sizes of magnetosomes were calculated as (length + width)/2 (Lin and Pan, 2009).

A1. The eMMP morphology, with flagella (grey arrow) covering the outer surface, (A2) bullet-shaped magnetosomes and (A3) energydispersive X-ray (EDX) analysis of an individual magnetosome (orange). The white square in (A1) shows the magnified area in (A2).

B. Vertical profiles of redox potential (green), eMMP abundance (red), magnetosome size (black) and the number of magnetosomes per cell (orange).

C. Magnetosomes of eMMPs from five sections of sediment depths. Note that the magnetosome chains lose organization in the $17-22 \mathrm{~cm}$ layer. 
In a previous study, greigite magnetosomes were occasionally observed in $\mathrm{Ca}$. M. rongchenensis (Chen et al., 2015). In this study, no greigite magnetosomes were found at all depths of the sediment with redox potentials of -247 to $253 \mathrm{mV}$ (Fig. 2B). A previous report indicated that the cultured MTB are responsive to external magnetic fields only when the dissolved oxygen concentration $\left(\mathrm{dO}_{2}\right)$ is below $1 \%$ (Zhang et al., 2011). In other studies, magnetite MTB start to synthesize magnetosomes only at a low $\mathrm{dO}_{2}$ level $\left(\leq 0.45 \mathrm{mg} / \mathrm{l}\right.$ at $26^{\circ} \mathrm{C}$ ), and high oxygen levels inhibit the formation of magnetite (Yang et al., 2001; Li and Pan, 2012). Thus, $\mathrm{dO}_{2}$ serves as a switch for the synthesis of magnetite magnetosomes. The synthesis of greigite magnetosomes in $\mathrm{Ca}$. M. rongchenensis was presumably triggered by a redox potential lower than those reached in this study.

Thus, the migration of eMMPs was orientated only by magnetite magnetosomes at all sediment depths. The occasionally observed greigite magnetosomes in $\mathrm{Ca}$. M. rongchenensis might play another role such as a container of excessive sulfur in low-redox potential environment.

\section{Environmental factors}

Temperature. In each sediment column, temperature varied slightly (less than $3.4^{\circ} \mathrm{C}$ ) among different depths and became stable in deeper sediment $(>5 \mathrm{~cm})$. The average temperature peaked in summer, at $25.4^{\circ} \mathrm{C}$, and reached its minimum in winter, at $1.2^{\circ} \mathrm{C}$. The average temperature in spring was slightly lower than that in autumn, $10.2^{\circ} \mathrm{C}$ and $16.8^{\circ} \mathrm{C}$ respectively (Fig. 1C). These results indicated that when the temperature was high (summer), eMMPs and sMMPs occurred within a narrow band in upper layers of sediment. When the temperature was low (winter), eMMPs and sMMPs were present at deeper layers. When the temperature was moderate (spring and autumn), eMMPs and sMMPs were widely present at middle layers (Fig. 1).

A previous study of the temporal distribution of eMMPs and SMMPs based on the upper $10 \mathrm{~cm}$ of sediment indicated that eMMPs preferred lower temperatures than sMMPs (Du et al., 2015). Considering the entire distribution depths of eMMPs and SMMPs, we calculated the average abundance of MMPs in each sediment column. The average abundance of eMMPs was slightly higher during spring $\left(36 \mathrm{ind} / \mathrm{cm}^{3}\right)$ than during other seasons $\left(30-31 \mathrm{ind} / \mathrm{cm}^{3}\right.$, Table 1). The average abundance of SMMPs was slightly higher during summer (38 ind $\left./ \mathrm{cm}^{3}\right)$ than during spring and autumn (31-33 ind/ $\mathrm{cm}^{3}$ ) but much higher than during winter $\left(19 \mathrm{ind} / \mathrm{cm}^{3}\right)$. Moreover, Student's $t$-test indicated that sMMPs were significantly more abundant at temperatures above $18^{\circ} \mathrm{C}$ and that eMMPs were significantly more abundant at temperatures below $18^{\circ} \mathrm{C}$ (Fig. 1D).
The average temperature of the sediment columns ranged from 0.1 to $27.1^{\circ} \mathrm{C}$ throughout the year; with the exception of the low average abundance of sMMPs in winter, the average abundances of both sMMPs and eMMPs were relatively uniform throughout the year (Table 1). As the temperature varied slightly (less than $3.4^{\circ} \mathrm{C}$ ) at different depths in each sediment column, temperature alone was not the direct cause of the vertical changes in MMP abundance.

Redox potential. Plots of the relationship between the oxidation-reduction potential (ORP) and MMP abundance indicated that the greatest abundance of eMMPs was present at ORPs from -179 to $-37 \mathrm{mV}$ and that the greatest abundance of sMMPs was present at ORPs from -82 to $+58 \mathrm{mV}$ (Fig. $3 \mathrm{~A}$ and $\mathrm{B}$ ). Thus, eMMPs preferred more reductive environments than sMMPs. The ORP depth profiles for four seasons indicated that MMPs preferred different layers during different seasons (Fig. 3C and D). The preferred layers of eMMPs were a depth of 4-8 cm during summer, 5-14 cm during spring and autumn and 15-20 cm during winter; sMMPs preferred the upper layers during summer $(2-5 \mathrm{~cm})$, spring (4-7 cm) and autumn $(4-7 \mathrm{~cm})$ but a deeper layer during winter $(7-14 \mathrm{~cm})$. These patterns were consistent with the vertical migration of these two types of MMPs, suggesting that vertical migration of MMPs between seasons correlates with the environmental redox potential.

The magnetosomes in MMPs play the same role as those in unicellular magnetotactic bacteria (Rodgers et al., 1990; Zhou et al., 2012). They confer on MMPs a net dipolar magnetic moment that allows MMP aligning and swimming along magnetic field lines. This behaviour is termed magnetotaxis. MMPs use magnetotaxis in combination with aerotaxis to seek the optimal redox potential in a vertical gradient in sediments. In a laboratory, when the consumption of oxygen modifies the gradient, the cultivated microaerobic MTB move upward and grow at a position closer to the air-liquid interface from where the oxygen penetrates and diffuses into the culture media (Zhang et al., 2014b). Here, we hypothesize a similar scenario for MMP distribution in the sediment. With seasonal changes, the redox potential values change throughout the sediment, which results in the relocalization of MMPs.

Bazylinski et al. have hypothesized that magnetoaerotaxis helps MMPs to seek electron donors or acceptors dynamically to keep a favourable internal redox state (Bazylinski et al., 2013). Cells with internally stored electron acceptors perform excursions from the upper sediment to anoxic deeper zones in order to accumulate reducing substances, that is, electron donors. Eventually, the depletion of electron acceptors and 

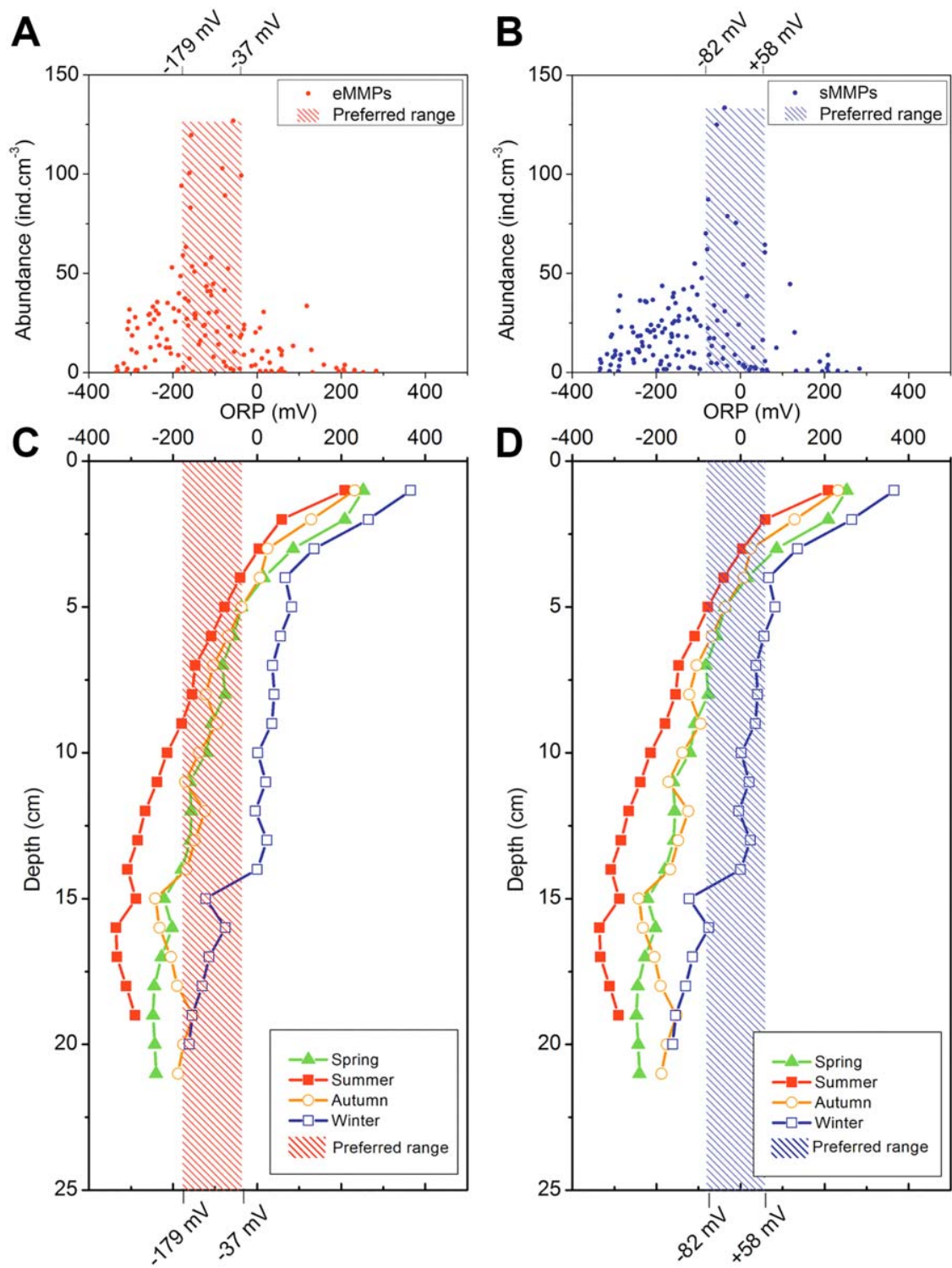

Fig. 3. Redox potential and its relationship with the abundances of eMMPs and sMMPs.

The ORP was measured in situ with three replicates at each sampling before the collection of sediment cores using a portable pH meter with a platinum electrode (length: $23 \mathrm{~cm}$ ) as the working electrode and a $\mathrm{Hg} / \mathrm{Hg}_{2} \mathrm{Cl}_{2}$ electrode (length: $21 \mathrm{~cm}$ ) as the reference electrode. The standard potential of the reference electrode $\left(U^{*}\right)$ at the measured temperature was added to the measured voltage $(U)$ to obtain the corrected redox voltage $\left(U_{\mathrm{H}}\right)$ :

$U_{H}=U+U^{\circ}$

$\mathrm{A}$ and $\mathrm{B}$. The eMMP abundance is greatest at redox potentials between -179 and $-37 \mathrm{mV}$ (left), and sMMP abundance is greatest at redox potentials between $-82 \mathrm{mV}$ and $+58 \mathrm{mV}$ (right).

$\mathrm{C}$ and D. Depth profiles of redox potential during four different seasons. The redox potentials preferred by eMMPs (left) and sMMPs (right) occur in different layers in different seasons.

accumulation of electron donors triggers the return of the cells to the upper sediment. For MMPs, the seasonal migration might be accomplished progressively with each magneto-aerotaxis. The long-distance migration depends on the strong swimming ability of the cells. In addition, we hypothesize that the thresholds of optimal redox potential reflect the ability of MMPs in storing electron donors or acceptors.
Inorganic nutrients. There were also changes in the vertical profiles of inorganic nutrients (Fig. 4). In particular, the profiles of $\mathrm{NH}_{4}^{+}$and $\mathrm{SiO}_{3}^{2-}$ were similar in that their highest concentrations occurred in the deep sediment during summer and early autumn, when the MMPs were most abundant in the shallow layers. This pattern suggested that high concentrations of $\mathrm{NH}_{4}^{+}$and $\mathrm{SiO}_{3}^{2-}$ might interfere with the vertical migration of MMPs. Additionally, both 


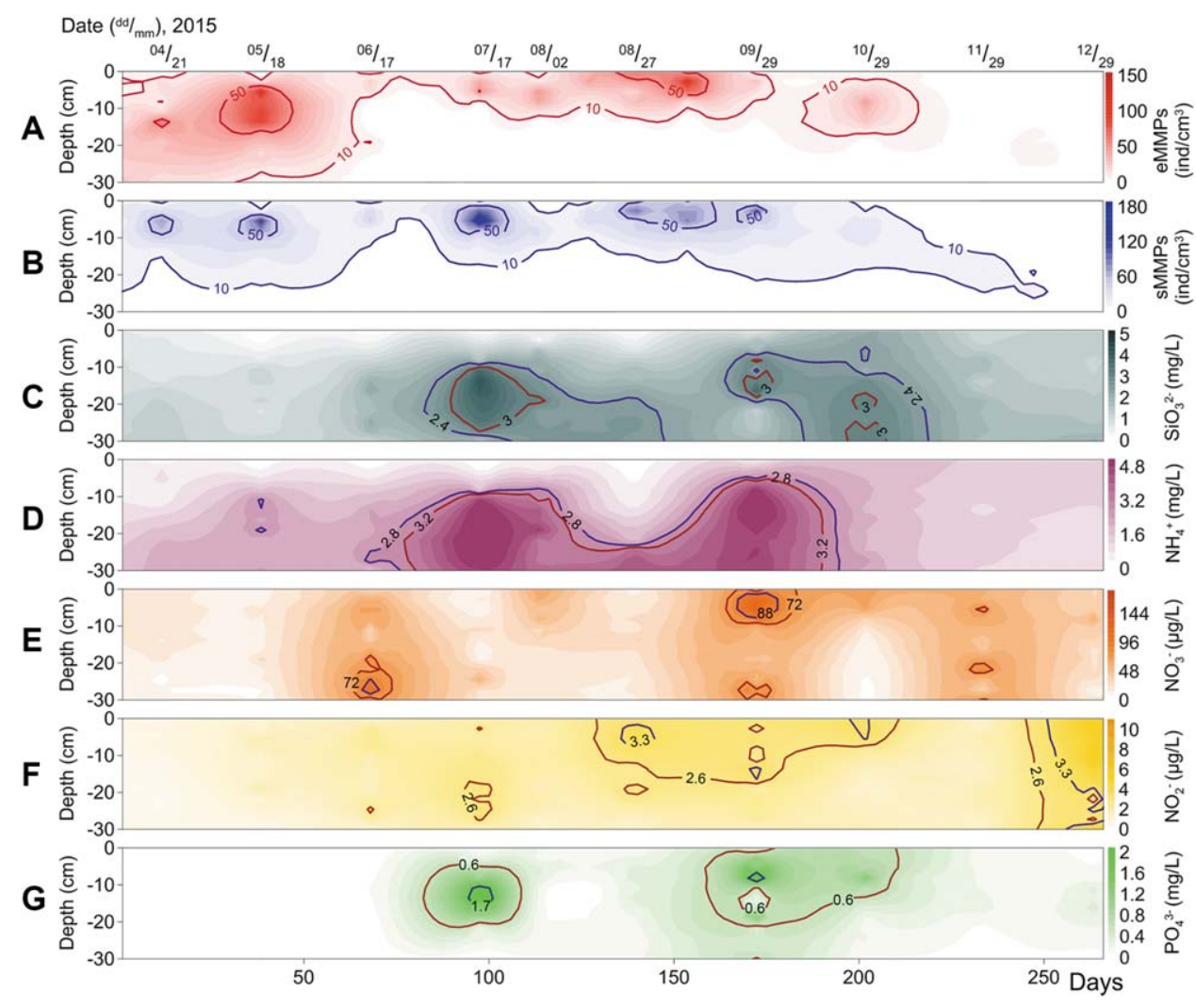

Fig. 4. MMP abundances and inorganic nutrient concentration at different sediment depths from April to December 2015.

Pore water was collected each time before the collection of sediment cores. The pore water collection was performed in field using a custommade collector with 30 syringes that could collect 30 layers of pore water at a time (Supporting Information Fig. S2). A SEAL QuAAtro 39-SFA Analyzer (Bran+Luebbe, Germany) was used to analyse the concentrations of inorganic nutrients in the pore water, including those of ammonium $\left(\mathrm{NH}_{4}^{+}\right)$, silicate $\left(\mathrm{SiO}_{3}^{2-}\right)$, nitrate $\left(\mathrm{NO}_{3}^{-}\right)$, nitrite $\left(\mathrm{NO}_{2}^{-}\right)$and phosphate $\left(\mathrm{PO}_{4}^{3-}\right)$.

$\mathrm{A}$ and B. Red lines (eMMPs) and blue lines (sMMPs) are isolines for $10 \mathrm{ind} / \mathrm{cm}^{3}$ and $50 \mathrm{ind} / \mathrm{cm}^{3}$ respectively.

C-G. Depth profiles of five inorganic nutrients and the upper limit of the preferred nutrient range for eMMPs (red lines) and sMMPs (blue lines). Note that high concentrations of $\mathrm{NH}_{4}^{+}$and $\mathrm{SiO}_{3}^{2-}$ occur at greater depths during summer and early autumn, when MMP abundance is generally lower.

types of MMPs preferred low concentration of inorganic nutrients (Supporting Information Fig. S1). The eMMPs preferred wider concentration ranges of $\mathrm{NH}_{4}^{+}, \mathrm{SiO}_{3}^{2-}$ and $\mathrm{NO}_{2}^{-}$, while sMMPs preferred wider concentration ranges of $\mathrm{NO}_{3}^{-}$and $\mathrm{PO}_{4}^{3-}$.

Principal component analysis (PCA). The first two axes of PCA ordination explained $52.81 \%$ of the total variance in MMP abundance (Fig. 5). The first axis was associated with the ORP $(26.9 \%), \mathrm{NH}_{4}^{+}$concentration $(21.8 \%)$, temperature $(16.6 \%)$ and $\mathrm{SiO}_{3}^{2-}$ concentration $(14.9 \%)$. In particular, high temperatures were associated with more reductive environments, reflecting the catabolism of organic matter. The high abundance of MMPs was associated with high temperatures and low redox potentials, suggesting the MMPs preferred an environment with active organic catabolism. All five inorganic nutrients were below the zero value on axis 2, whereas the abundance of MMPs was above this value, indicating that both types of MMPs preferred low-inorganic-nutrient environments. The distribution pattern of seasonal samples showed a clear separation into three groups. The environmental conditions during winter were much different from those during other seasons, and the environmental conditions were very similar during summer and autumn.

\section{Conclusion}

Taken together, our data indicated the seasonal variations in the vertical distributions of eMMPs and sMMPs. Ca. M. rongchenensis, with magnetite magnetosomes, migrated between different depths. ORP, a measure of the oxidizing and reducing nature of the environment, had a strong relationship with MMP migration. MMPs preferred low concentrations of all five tested inorganic nutrients and migrate away from high concentrations of $\mathrm{NH}_{4}^{+}$and $\mathrm{SiO}_{3}^{2-}$. Here, we identified some environmental factors related to the abundance and vertical migration of MMPs. Further genomic studies and studies of the behaviour 


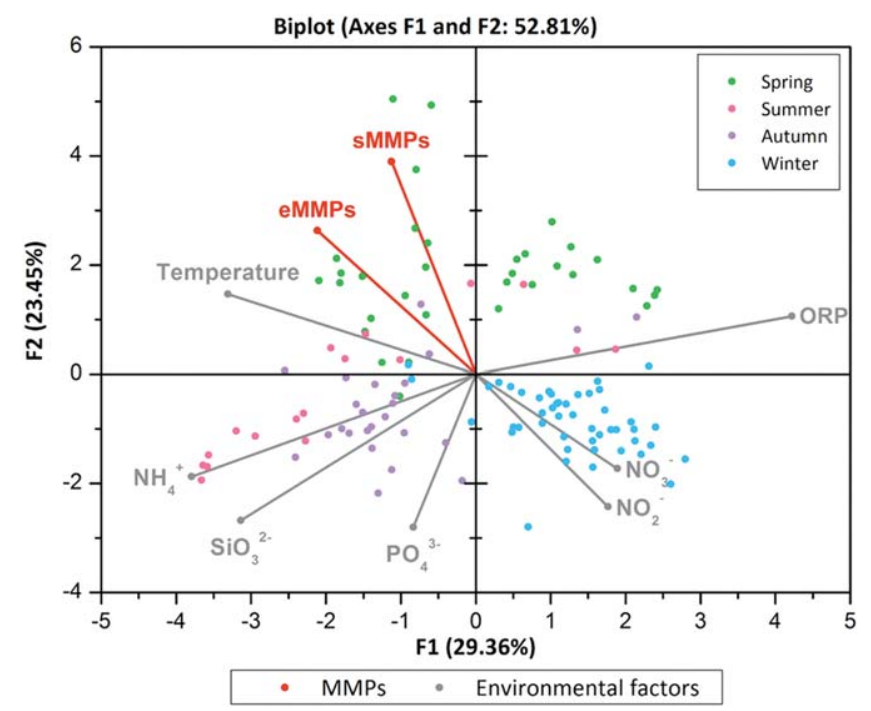

Fig. 5. Principal component analysis of MMP abundance and environmental factors.

Principal component analysis (PCA) using Pearson's matrix and principal components (PC) axis scores was used using XLSTAT-Pro 19. The first two principal components (PCs) (F1 and F2) account for $52.81 \%$ of the total variance. The first axis (F1) is associated with redox potential, $\mathrm{NH}_{4}^{+}$concentration, temperature and $\mathrm{SiO}_{3}^{2-}$ concentration, and the second axis (F2) is associated with eMMP abundance, sMMP abundance, $\mathrm{PO}_{4}^{3-}$ concentration, $\mathrm{NO}_{3}^{-}$concentration and $\mathrm{NO}_{2}^{-}$concentration. Redox potential is the most important environmental factor and accounts for $26.9 \%$ of the seasonal changes in MMP abundance. Note that the five inorganic nutrients and abundance of eMMPs and sMMPs are on opposite sides of axis F2, indicating that MMPs prefer low-nutrient environments. Note also the clear separation into three seasonal groups, indicating that the environmental conditions during winter (blue) are different from those during other seasons and that the environmental conditions during summer (pink) and autumn (purple) are similar.

and physiology of MMPs will provide important information on the underlying metabolic mechanisms.

\section{Acknowledgements}

This study was supported by the National Natural Science Foundation of China (NSFC, Grant Nos. 41330962, U1706208, 41776130 and 41776131). We thank X. Zheng for collecting the sediment samples. The TEM analyses were performed at KLEMB, IOCAS, with the assistance of W. Liu. We thank Dr. J. Sun (Tianjin University of Science and Technology) for conducting the inorganic nutrient analyses.

\section{References}

Abreu, F., Martins, J.L., Silveira, T.S., Keim, C.N., de Barros, H.G., Filho, F.J., and Lins, U. (2007) 'Candidatus Magnetoglobus multicellularis', a multicellular, magnetotactic prokaryote from a hypersaline environment. Int $J$ Syst Evol Microbiol 57: 1318-1322.

Amann, R., Peplies, J., and Schüler, D. (2006) Diversity and taxonomy of magnetotactic bacteria. In Magnetoreception and Magnetosomes in Bacteria. Schüler, D. (ed.). Berlin, Heidelberg: Springer-Verlag, pp. 25-36.

Bazylinski, D.A., Lefèvre, C.T., and Schüler, D. (2013) Magnetotactic bacteria. In The Prokaryotes. Rosenberg, E. (ed.). Berlin, Heidelberg: Springer, pp. 453-494.

Chen, Y.R., Zhang, R., Du, H.J., Pan, H.M., Zhang, W.Y., Zhou, K. et al, (2015) A novel species of ellipsoidal multicellular magnetotactic prokaryotes from Lake Yuehu in China. Environ Microbiol 17: 637-647.
Chen, Y.R., Zhang, W.Y., Zhou, K., Pan, H.M., Du, H.J., Xu, C. et al, (2016) Novel species and expanded distribution of ellipsoidal multicellular magnetotactic prokaryotes. Environ Microbiol Rep 8: 218-226.

Du, H.J., Chen, Y.R., Zhang, R., Pan, H.M., Zhang, W.Y., Zhou, K. et al, (2015) Temporal distributions and environmental adaptations of two types of multicellular magnetotactic prokaryote in the sediments of Lake Yuehu, China. Environ Microbiol Rep 7: 538-546.

Farina, M., Debarros, H.L., Esquivel, D.M.S., and Danon, J. (1983) Ultrastructure of a Magnetotactic Microorganism. Biol Cell 48: 85-88.

Greenberg, M., Canter, K., Mahler, I., and Tornheim, A. (2005) Observation of magnetoreceptive behavior in a multicellular magnetotactic prokaryote in higher than geomagnetic fields. Biophys J 88: 1496-1499.

Keim, C.N., Abreu, F., Lins, U., Lins de Barros, H., and Farina, M. (2004a) Cell organization and ultrastructure of a magnetotactic multicellular organism. J Struct Biol 145: 254-262.

Keim, C.N., Martins, J.L., Abreu, F., Rosado, A.S., de Barros, H.L., Borojevic, R. et al, (2004b) Multicellular life cycle of magnetotactic prokaryotes. FEMS Microbiol Lett 240: 203-208.

Keim, C.N., Martins, J.L., de Barros, H.L., Lins, U., and Farina, M. (2006) Structure, behavior, ecology and diversity of multicellular magnetotactic prokaryotes. In Magnetoreception and Magnetosomes in Bacteria. Schüler, D. (ed.). Berlin, Heidelberg: Springer-Verlag, pp. 103-132.

Kolinko, S., Jogler, C., Katzmann, E., Wanner, G., Peplies, J., and Schüler, D. (2012) Single-cell analysis reveals a novel uncultivated magnetotactic bacterium within the 
candidate division OP3. Environ Microbiol 14: 17091721.

Leão, P., Chen, Y.R., Abreu, F., Wang, M.L., Zhang, W.J., Zhou, K. et al, (2017) Ultrastructure of ellipsoidal magnetotactic multicellular prokaryotes depicts their complex assemblage and cellular polarity in the context of magnetotaxis. Environ Microbiol 19: 2151-2163.

Lefèvre, C., Bernadac, A., Pradel, N., Wu, L., Yu-Zhang, K., Xiao, T. et al, (2007) Characterization of Mediterranean magnetotactic bacteria. J Ocean Univ China 6: 355-359.

Lefèvre, C.T., Abreu, F., Lins, U., and Bazylinski, D.A. (2010) Nonmagnetotactic multicellular prokaryotes from low-saline, nonmarine aquatic environments and their unusual negative phototactic behavior. Appl Environ Microbiol 76: 3220-3227.

Li, J., and Pan, Y. (2012) environmental factors affect magnetite magnetosome synthesis in Magnetospirillum magneticum AMB-1: implications for biologically controlled mineralization. Geomicrobiol J 29: 362-373.

Lin, W., and Pan, Y. (2009) Uncultivated magnetotactic cocci from yuandadu park in beijing, china. Appl Environ Microbiol 75: 4046-4052.

Martins, J.L., Silveira, T.S., Abreu, F., de Almeida, F.P., Rosado, A.S., and Lins, U. (2012) Spatiotemporal distribution of the magnetotactic multicellular prokaryote Candidatus Magnetoglobus multicellularis in a Brazilian hypersaline lagoon and in microcosms. Int Microbiol 15: 141-149.

Moskowitz, B.M., Bazylinski, D.A., Egli, R., Frankel, R.B., and Edwards, K.J. (2008) Magnetic properties of marine magnetotactic bacteria in a seasonally stratified coastal pond (Salt Pond, MA, USA). Geophys J Int 174: 75-92.

Rodgers, F.G., Blakemore, R.P., Blakemore, N.A., Frankel, R.B., Bazylinski, D.A., Maratea, D., and Rodgers, C. (1990) Intercellular Structure in a Many-Celled Magnetotactic Prokaryote. Arch Microbiol 154: 18-22.

Simmons, S.L., and Edwards, K.J. (2007) Unexpected diversity in populations of the many-celled magnetotactic prokaryote. Environ Microbiol 9: 206-215.

Simmons, S.L., Sievert, S.M., Frankel, R.B., Bazylinski, D.A., and Edwards, K.J. (2004) Spatiotemporal distribution of marine magnetotactic bacteria in a seasonally stratified coastal salt pond. Appl Environ Microbiol 70: 6230-6239.

Simmons, S.L., Bazylinski, D.A., and Edwards, K.J. (2007) Population dynamics of marine magnetotactic bacteria in a meromictic salt pond described with qPCR. Environ Microbiol 9: 2162-2174.

Sobrinho, R.L., Lins, U., and Bernardes, M.C. (2011) Geochemical Characteristics Related to the GregiteProducing Multicellular Magnetotactic Prokaryote Candidatus Magnetoglobus multicellularisin a Hypersaline Lagoon. Geomicrobiol J 28: 705-713.
Wenter, R., Wanner, G., Schüler, D., and Overmann, J. (2009) Ultrastructure, tactic behaviour and potential for sulfate reduction of a novel multicellular magnetotactic prokaryote from North Sea sediments. Environ Microbiol 11: 1493-1505.

Yang, C.D., Takeyama, H., Tanaka, T., and Matsunaga, T. (2001) Effects of growth medium composition, iron sources and atmospheric oxygen concentrations on production of luciferase-bacterial magnetic particle complex by a recombinant Magnetospirillum magneticum AMB-1. Enzyme Microb Technol 29: 13-19.

Zhang, Y., Zhang, X., Jiang, W., Li, Y., and Li, J. (2011) Semicontinuous culture of Magnetospirillum gryphiswaldense MSR-1 cells in an autofermentor by nutrientbalanced and isosmotic feeding strategies. Appl Environ Microbiol 77: 5851-5856.

Zhang, R., Chen, Y.R., Du, H.J., Zhang, W.Y., Pan, H.M., Xiao, T., and Wu, L.F. (2014a) Characterization and phylogenetic identification of a species of spherical multicellular magnetotactic prokaryotes that produces both magnetite and greigite crystals. Res Microbiol 165: 481-489.

Zhang, S.D., Petersen, N., Zhang, W.J., Cargou, S., Ruan, J., Murat, D. et al, (2014b) Swimming behaviour and magnetotaxis function of the marine bacterium strain $\mathrm{MO}$ 1. Environ Microbiol Rep 6: 14-20.

Zhou, K., Pan, H., Zhang, S., Yue, H., Xiao, T., and Wu, L. (2011) Occurrence and microscopic analyses of multicellular magnetotactic prokaryotes from coastal sediments in the Yellow Sea. Chin J Oceanol Limnol 29: 246-251.

Zhou, K., Zhang, W.Y., Yu-Zhang, K., Pan, H.M., Zhang, S.D., Zhang, W.J. et al, (2012) A novel genus of multicellular magnetotactic prokaryotes from the Yellow Sea. Environ Microbiol 14: 405-413.

Zhou, K., Zhang, W.Y., Pan, H.M., Li, J.H., Yue, H.D., Xiao, T., and Wu, L.F. (2013) Adaptation of spherical multicellular magnetotactic prokaryotes to the geochemically variable habitat of an intertidal zone. Environ Microbiol 15: 1595-1605.

\section{Supporting Information}

Additional Supporting Information may be found in the online version of this article at the publisher's web-site:

Fig. S1. Relationship of concentrations of different inorganic nutrients with abundance of eMMPs (a1-e1) and sMMPs (a2-e2). Note that eMMPs and sMMPs are generally more abundant at low nutrient concentrations. The eMMPs have broader preferred ranges for $\mathrm{NH}_{4}^{+}$concentration (a1, a2), $\mathrm{SiO}_{3}^{2-}$ concentration (b1, b2) and $\mathrm{NO}_{2}^{-}$concentration (c1, c2) while sMMPs have broader preferred ranges for $\mathrm{NO}_{3}^{-}$ concentration (d1, d2) and $\mathrm{PO}_{4}^{3-}$ concentration (e1, e2).

Fig. S2. Custom-made pore water collector. 